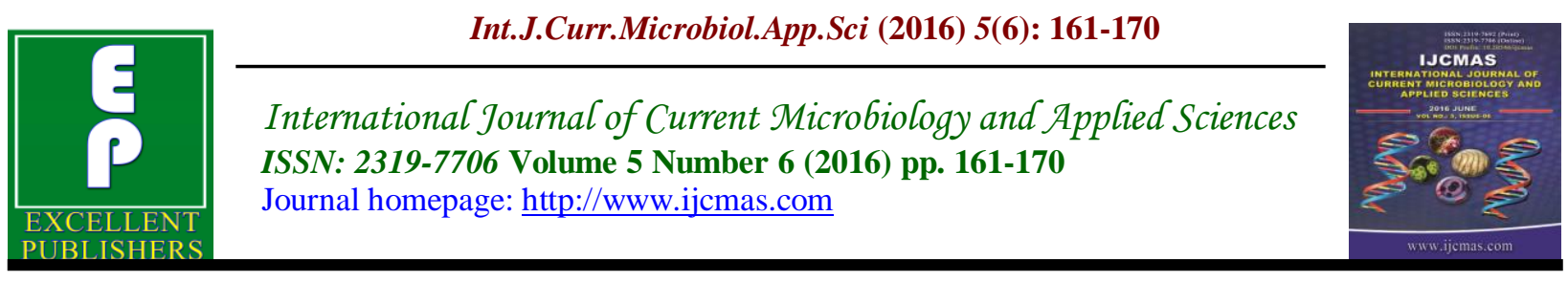

Original Research Article

http://dx.doi.org/10.20546/ijcmas.2016.506.020

\title{
A Comparative Study of Aeromycoflora in Traffic and Residential Areas of Haridwar City, India
}

\author{
Raushani Raj* and Namita Joshi \\ Department of Environmental Sciences, Kanya Gurukula Campus, Gurukula Kangri \\ University, Haridwar (Uttarakhand), India \\ *Corresponding author
}

\begin{abstract}
A B S T R A C T
Keywords

Aeromycoflora, Indoor and Outdoor environment, Relative humidity, Fungal spores.

\section{Article Info}

Accepted:

11 May 2016

Available Online:

10 June 2016

A comparative study of the aeromycoflora in traffic and residential areas of Haridwar City were studied during January- March 2014. The present work was based on the collection of fungal spores from the atmospheric air from the spore trapper technique. Potato Dextrose media was used for the present study. For air sampling, exposed Petri Plate method was used. The investigation showed variations in number as well as in the composition of fungal species of these areas. The maximum average value of colony forming unit of fungal colonies after plate exposure was recorded as $92.5 \mathrm{c} / \mathrm{m}^{3}$ from site II and its minimum average value was recorded as $60.75 \mathrm{c} / \mathrm{m}^{3}$ from site III. The study revealed that the fungal spores were the major components of the air micro flora of both the outdoor and indoor environment of Haridwar city. A total of 13 types of fungi were recognized from both the outdoor and indoor environment and there were some species which could not be identified. Aspergillus and Penicillium were reported as dominant species of the outdoor environment where as Cladosporium was dominant species followed by Rhizopus and Mucor at residential areas. Other genera like Alternaria, Fusarium., Helminthosporium, were frequently recorded from both the crosssection circles of the city where as Trichoderma was the least dominant species occurred at both the outdoor and indoor environment.
\end{abstract}

\section{Introduction}

Air is one of the most important abiotic environmental component and essential for the existence of life, (Joshi, 1995). Air pollution in India is a serious issue with the major sources being fuel wood and biomass burning, fuel adultery action, vehicle emission and traffic congestion. Traffic congestion is severe in India in cities and towns, (Awasthi, 2008). The atmosphere contains all the major groups of microbes ranging from the viruses to fungi, (Waggoner, 1960). Fungal spores, commonly called mold spores, are a normal component of the outdoor air. The spores are discharged from fungi growing as saprophytes (existing on dead or decaying organic matter in the soil or elsewhere in the environment) or parasites (infecting living tissues), (Levetin et al., 2004). Anytime, moisture or even high humidity is available, spores can germinate and fungi can grow 
and produce thousands of new spores, (Levetin, 1995). Air borne fungal spore occur throughout almost the whole year, but the seasonal rhythm in the occurrence of air borne spores and their spectrum depends on the type of climate (Adhikari et al., 2004). The fungal densities in the air also vary in accordance with geographical regions and seasons, besides the physical parameters such as wind direction, humidity, temperature, precipitation and altitude. The fungal species such as Penicillium, Aspergillus, Mucor, Fusarium and Cladosporium are the dominant fungi in the atmospheric air, (Das and Bhattacharya, 2008). High temperature and the absence of rain are unfavourable conditions for the growth of fungus.

Many fungal spores are allergic capable of causing allergenic responses in susceptible individuals. Epidemiological studies showed that too high concentration of microorganisms in the air can be allergic, however even very low concentrations of some particular microorganisms can cause serious diseases. Human exposure to airborne micro-organisms may result in a variety of adverse health effects including infectious diseases like legionmelosis, Eczema, Onchomycosis, Otomycosis, allergic and irritant responses respiratory problems and hyper sensitivity reactions, (Chandel, 2002). Keeping these facts in view, the present study was designed to evaluate the relative occurrence of certain air borne mycofloral proportions of four different sites in Haridwar city pertaining to different conditions i.e. residential and traffic cross section circles of the city.

\section{Material and Methods}

\section{Study Area}

The present study was conducted at four different sites in Haridwar district located in the state of Uttarakhand, two sites of traffic area with Site I (Singh Dwar) and Site II (Jatwara Pul) with heavy pollution load and two sites of residential area with Site III (Vishnu Garden Colony) and Site IV (Gyan Lok Colony) with light pollution load. The study was conducted during winter season for twelve weeks i.e., from January 2014 to March 2014.

Standard procedures were followed in analyzing the samples as prescribed by Aneja, 2003; Watanbe, 2002.

\section{Procedure for Sampling}

For air sampling exposed Petri plate method was used. The method of trapping spores by Petri-plates exposure involves the principle of sedimentation under the force of gravity. Four Petri plates $(10 \mathrm{~cm}$ diameter) of freshly poured potato dextrose agar medium were exposed at each site for 10 minutes in afternoon at an interval of 10 days. Plates were exposed at one meter height from ground level at both the sides. Temperature and relative humidity were also recorded with the help of thermometer and hygrometer respectively at the time of exposure. After exposure, the plates were incubated at $28 \pm^{\circ} \mathrm{C}$ for 3-4 days in incubator.

\section{Calculations}

After incubation, the colonies on plates were counted with the help of electronic colony counter.

C.F.U. $=$ Total number of colonies

Total Occurrence $=\frac{\begin{array}{c}\text { Novof Colonies of Individual } \\ \text { Species in all Plate Studied }\end{array}}{\begin{array}{c}\text { Total Novf Colonies } \\ \text { of all the Species }\end{array}} \times 100$

The microscopic examination of fungi was done by using Agar squash mount method given in (Watanbe, 2002). 


\section{Results and Discussion}

The present work was based on the collection of fungal spores from the atmospheric air by spore trapping technique. This work was carried out at four different locations from residential and traffic cross section circles of Haridwar city. The results of present study are given in Table I, Table II and Table III A total of 13 fungal species were identified viz. Aspergillus niger, Aspergillus fumigatus, Aspergillus flavus, Alternaria, Cladosporium, Fusarium, Helminthosporium, Mortierella, Mucor, Nigrospora, Penicillium, Rhizopus and Trichoderma. Some species were unidentified.

The mean temperature and mean relative humidity of the atmosphere from the month of January to March are given in Table I. The mean temperature of the atmosphere was increased from $11.9^{\circ} \mathrm{C}$ to $21.9^{\circ} \mathrm{C}$ from the month of January to March and the relative humidity of the atmosphere was also increased from $50.5 \%$ in January to $53.5 \%$ in the month of March.

A total mean of 82.25 and 92.5 colonies were trapped from traffic circles on exposed Petri-plates at site I and Site II respectively after the sampling, which is shown in table II. A total mean of 60.75 and 70.25 colonies were trapped from residential areas on exposed Petri plates at Site III and Site IV respectively, which is shown in Table III. Maximum number of colonies were recorded in the later study period due to increase in temperature up to $23^{\circ} \mathrm{C}$. The maximum numbers of colonies were counted from the exposed Petri plates $\left(92.5 \mathrm{c} / \mathrm{m}^{3}\right)$ at site II, $82.25 \mathrm{c} / \mathrm{m}^{3}$ at site I followed by $70.25 \mathrm{c} / \mathrm{m}^{3}$ at site IV. The lowest numbers of colonies were recorded from Site III $\left(60.75 \mathrm{C} / \mathrm{m}^{3}\right)$. Table IV is indicating the relative occurrrence of fungi at four different sampling sites.
During the course of study, the genus Aspergillus accounted maximum at site I $(23.40 \%)$ and minimum at site IV $(20.50 \%)$. Different species of Aspergillus were identified, including Aspergillus flavus, Aspergillus fumigates and Aspergillus niger. Aspergillus flavus was found maximum at site II (10\%) due to regular human activities and heavy load of vehicular pollution. Alternaria. was found in frequency on exposed plates at site II and site III accounting $7.02 \%$ and $7.85 \%$ respectively of the total occurrence. Alternaria is a genus of ascomycete fungi. The occurrence of Cladosporium was found to be maximum $14.02 \%$ at site IV and minimum $9.72 \%$ at site I along with $10.27 \%$ at site II and 13.22 $\%$ at site III. Cladosporium is a genus of fungi including some of the most common indoor and outdoor molds. The percentage occurrence of Fusarium was found to be maximum at site III $(6.19 \%)$ and minimum at site II (1.35\%) along with (3.33\%) at site I and $(3.23 \%)$ at site IV. Fusarium is a fungi of class Deuteromycetes. Helminthosporium was found in higher frequency on exposed plates of site III and site I accounting 7.43\% and $6.07 \%$ respectively followed by $5.13 \%$ at site II and $5.39 \%$ at site IV. Colonies of Mortierella were counted highest from the exposed petriplates at site II $(6.48 \%)$ and lowest at site III (3.30\%) followed by $6.38 \%$ at site II and $5.03 \%$ at site IV. In the present study, the occurrence of Mortierella was more in traffic areas than the residential areas. Occurrence of Mucor was found to be maximum $12.58 \%$ at site IV and minimum at site II $10.54 \%$ along with $12.51 \%$ at site I and $12.39 \%$ at site III. The present study showed the maximum occurrence of Nigrospora $5.03 \%$ at site IV and minimum $3.95 \%$ at site I along with $4.59 \%$ at site II. Nigrospora was not present at site III. The occurrence of Nigrospora was more at traffic areas when compared with residential areas. In the present study, the percentage 
occurrence of Penicillium was found to be maximum at site II with $10.54 \%$ and minimum at $4.31 \%$ at site IV along with $8.81 \%$ for site I and $4.54 \%$ for site III. Penicillium is a genus of Ascomycetes fungi of major importance in the natural environment as well as food and drug production. The present study showed the highest percentage of Rhizopus at site IV $(12.43 \%)$ and minimum at site I $(9.42 \%)$ along with (10.27\%) at site II and (10.74\%) at site III. Rhizopus is a fungus comes in order of Zygomycetes and grow as saprophytes on a wide variety of organic substates like bread, jellies, syrups, leather etc. The percentage occurrence of Trichoderma was $(4.13 \%)$ at site III along with $(4.05 \%)$ at site II, $(3.95 \%)$ at site IV and $3.64 \%$ at site I. Trichoderma is a genus of fungi that is present in all soils, where they are the most prevalent culturable fungi. The colonies of Trichoderma are generally white to green in colour. There were some species which could not be identified during the study period. The percentage occurrence of unidentified species at site I was $(6.99 \%)$ along with $(6.75 \%)$ at site II, $(8.67 \%)$ at site III and $(6.83 \%)$ at site IV.

The abundance of airborne fungal spores reveal specific variation pattern which can be correlated with changes in metrological factors such as temperature and relative humidity. During the entire work, the lowest temperature was during January $\left(11.9^{\circ} \mathrm{C}\right)$, the fungal colonies and species were also decreased. An increase in temperature and relative humidity resulted in high occurrence of mycoflora. Afzal et al., (2004) observed that increased degree of temperature caused significant increase in species and colonies of fungi during the summer season. Tan et $a l .$, (1992) reported that spore load is related with relative humidity. Ahmad (1960) discussed that due to temperature and relative humidity, spore's productivity is affected. In the present study, during the month of March, there was increase in percentage of fungal colonies during the later study period which were associated with relative humidity and temperature, while in February, there were low no. number of fungal colonies due to decrease in relative humidity and temperature. The important factor on which the colony count depends is the type of media used. In this work, Potato Dextrose Agar media was used for the growth of fungi. The results are not easily compared mainly because of the different sampling techniques that different authors used. According to Sabariego et al., (2007), very high temperature and absence of rain are unfavorable conditions for the growth of fungus.

Table.1 Values of atmospheric mean temperature and mean relative humidity during the study period

\begin{tabular}{|c|c|c|}
\hline Month & Mean temperature $\left({ }^{\circ} \mathrm{C}\right) \pm$ S.E & $\begin{array}{c}\text { Mean relative humidity } \\
(\%) \pm \text { S.E }\end{array}$ \\
\hline January & $11.9 \pm 0.02$ & $50.5 \pm 0.33$ \\
\hline February & $19.4 \pm 0.25$ & $50.5 \pm 0.22$ \\
\hline March & $21.9 \pm 0.25$ & $53.5 \pm 0.33$ \\
\hline
\end{tabular}


Table.2 Values of colony forming unit of fungal colonies after plate exposure at different traffic sites. (All values are mean \pm S.E. for 6 observation each)

\begin{tabular}{|c|c|c|}
\hline Sl. No. & Site I (Singh Dwar) & Site II (Jatwara Pul) \\
\hline I. & $11.75 \pm 0.85$ & $13.75 \pm 0.92$ \\
\hline II. & $14.25 \pm 0.94$ & $12.0 \pm 0.86$ \\
\hline III. & $12.75 \pm 0.89$ & $14.25 \pm 0.94$ \\
\hline IV. & $13.25 \pm 0.91$ & $16.75 \pm 1.02$ \\
\hline V. & $13.0 \pm 0.90$ & $17.0 \pm 1.03$ \\
\hline VI. & $17.25 \pm 1.03$ & $18.75 \pm 1.08$ \\
\hline Total CFU c/m & $82.25 \mathrm{c}^{3}$ & $92.5 \mathrm{c}^{3}$ \\
\hline
\end{tabular}

Table.3 Values of colony forming unit of fungal colonies after plate exposure at different residential sites. (All values are mean \pm S.E. for 6 observation each)

\begin{tabular}{|c|c|c|}
\hline Sl. No. & Site III (Vishnu Garden Colony) & Site IV (Gyan Lok Colony) \\
\hline I. & $8.25 \pm 0.72$ & $12.0 \pm 0.86$ \\
\hline II. & $9.5 \pm 0.77$ & $10.75 \pm 0.81$ \\
\hline III. & $9.25 \pm 0.72$ & $11.5 \pm 0.84$ \\
\hline IV. & $11.25 \pm 0.83$ & $11.0 \pm 0.82$ \\
\hline V. & $10.0 \pm 0.79$ & $12.25 \pm 0.87$ \\
\hline VI. & $12.5 \pm 0.88$ & $12.75 \pm 0.89$ \\
\hline Total CFU c/m & $60.75 \mathrm{c}^{3}$ & $70.25 \mathrm{c}^{3}$ \\
\hline
\end{tabular}

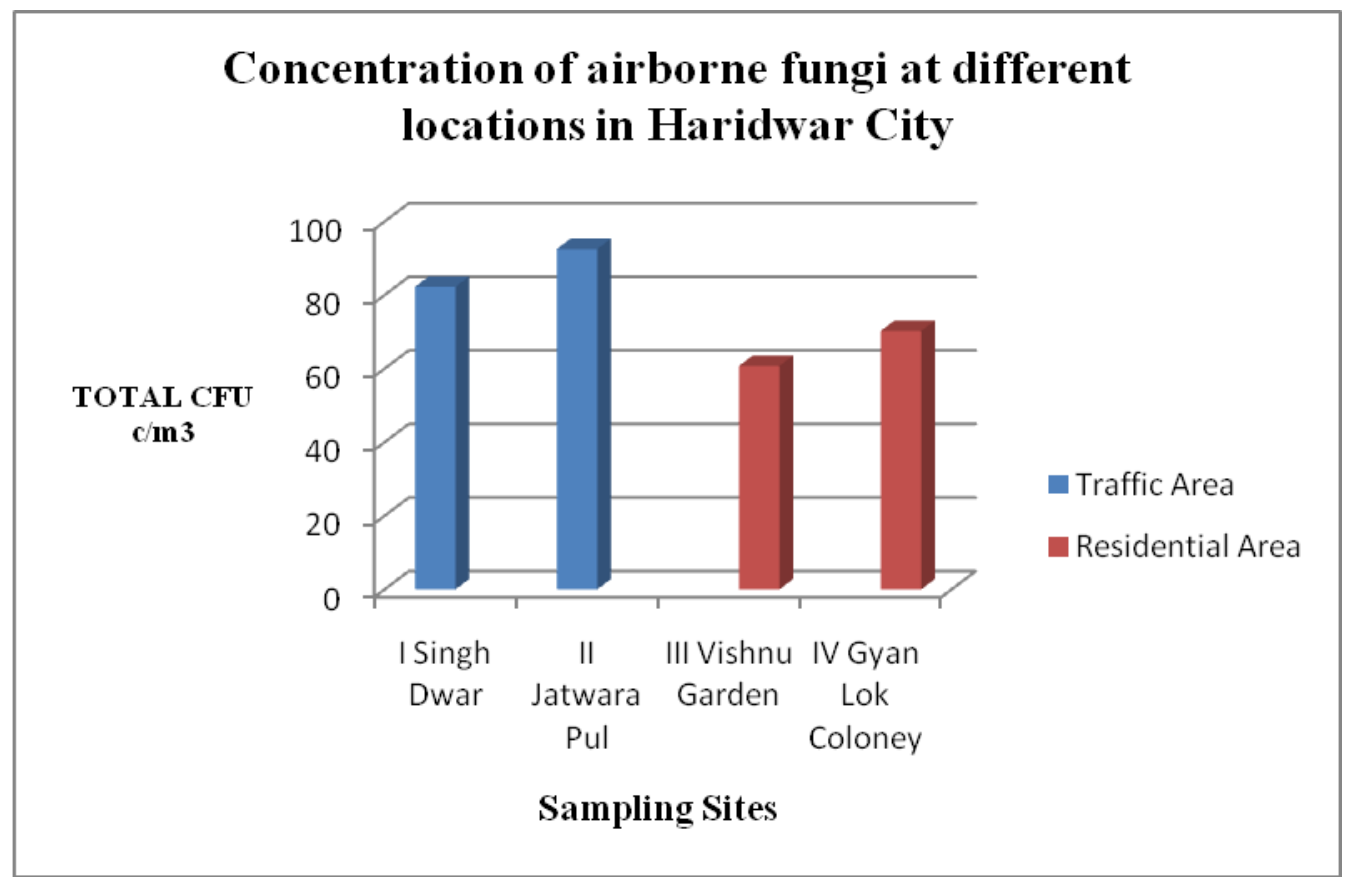

Figure.1 Values of colony forming units of Fungi at Traffic and Residential sites 
Table.4 Relative Occurrence of Fungal Spores trapped through Cultured Petri plates at Different Sites

\begin{tabular}{|l|l|c|c|c|c|}
\hline \multirow{2}{*}{ SL.No. } & \multirow{2}{*}{ Name of Fungi } & \multicolumn{2}{|c|}{ Traffic Area } & \multicolumn{2}{c|}{ Residential Area } \\
\cline { 3 - 5 } & & Site I & Site II & Site III & Site IV \\
\cline { 3 - 5 } & & $\begin{array}{c}\text { R.O. of } \\
\text { Species (\%) }\end{array}$ & $\begin{array}{c}\text { R.O. of } \\
\text { Species (\%) }\end{array}$ & $\begin{array}{c}\text { R.O. of } \\
\text { Species (\%) }\end{array}$ & $\begin{array}{c}\text { R.O. of Species } \\
(\%)\end{array}$ \\
\hline 1 & Aspergillus sp. & 23.40 & 22.43 & 21.48 & 20.50 \\
\hline I & A.flavus & 7.90 & 10 & 6.19 & 5.03 \\
\hline II & A.fumigatus & 6.38 & 5.13 & 7.02 & 8.99 \\
\hline III & A.niger & 9.11 & 7.29 & 8.26 & 9.71 \\
\hline 2 & Alternaria & 6.07 & 7.02 & 7.85 & 6.83 \\
\hline 3 & Cladosporium & 9.72 & 10.27 & 13.22 & 14.02 \\
\hline 4 & Fusarium & 3.33 & 1.35 & 6.19 & 3.23 \\
\hline 5 & Helminthosporium & 6.07 & 5.13 & 7.43 & 5.39 \\
\hline 6 & Mortierella & 6.38 & 6.48 & 3.30 & 5.03 \\
\hline 7 & Mucor & 12.15 & 10.54 & 12.39 & 12.58 \\
\hline 8 & Nigrospora & 3.95 & 4.59 & - & 5.03 \\
\hline 9 & Penicillium & 8.81 & 10.54 & 4.54 & 4.31 \\
\hline 10 & Rhizopus & 9.42 & 10.27 & 10.74 & 12.43 \\
\hline 11 & Trichoderma & 3.64 & 4.05 & 4.13 & 3.95 \\
\hline 12 & Unidentified $\mathbf{s p .}$ & 6.99 & 6.75 & 8.67 & 6.83 \\
\hline
\end{tabular}

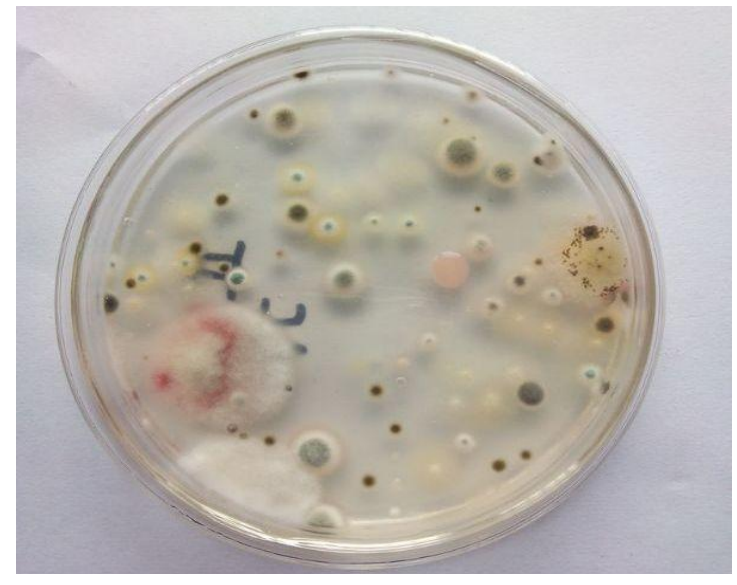

Photo plate 1

Showing early study of Fungal colonies at site I

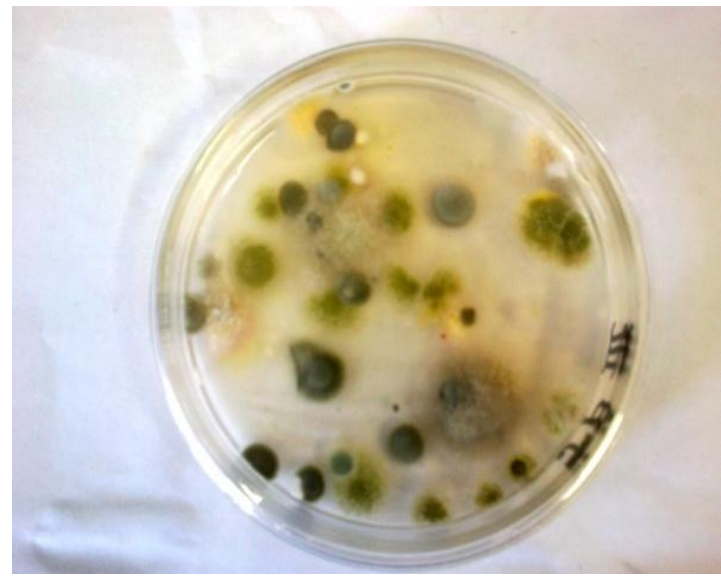

Photo plate 2 Showing later study of Fungal colonies at site I. 


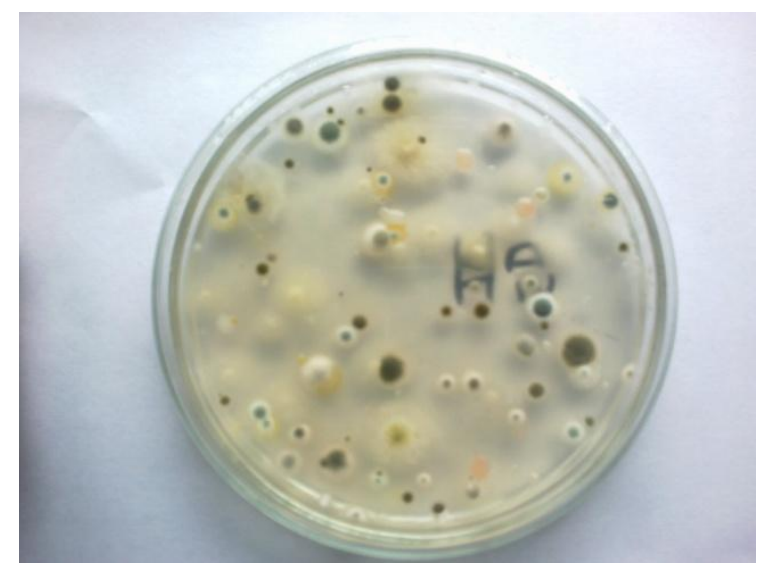

Photo plate 3

Showing early study of Fungal colonies at site II.

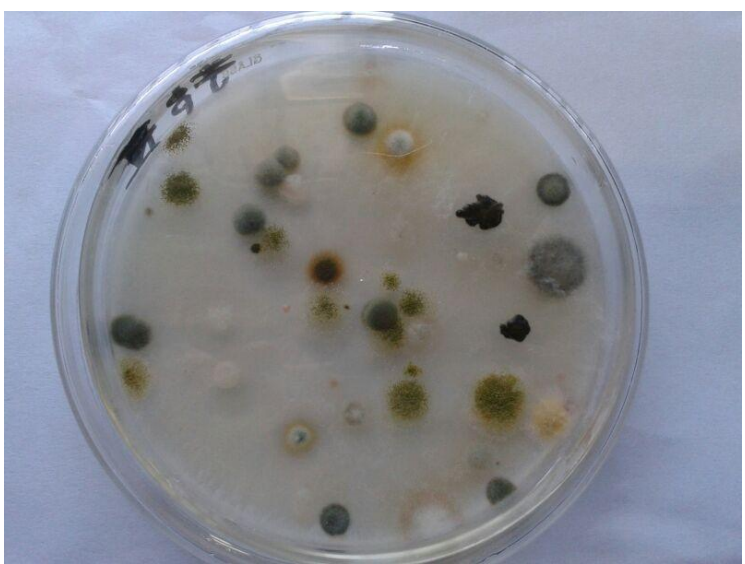

Photo plate 5

Showing early study of Fungal colonies at site III.

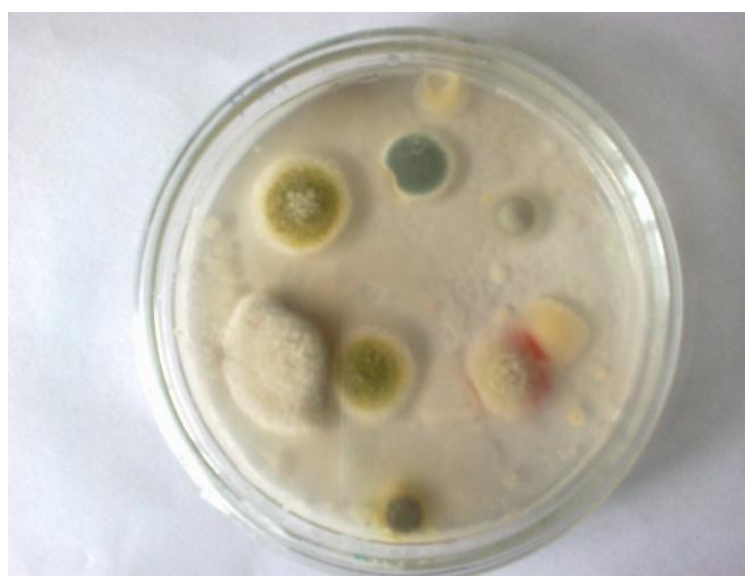

Photo plate 7

Showing early study of Fungal colonies at site IV.

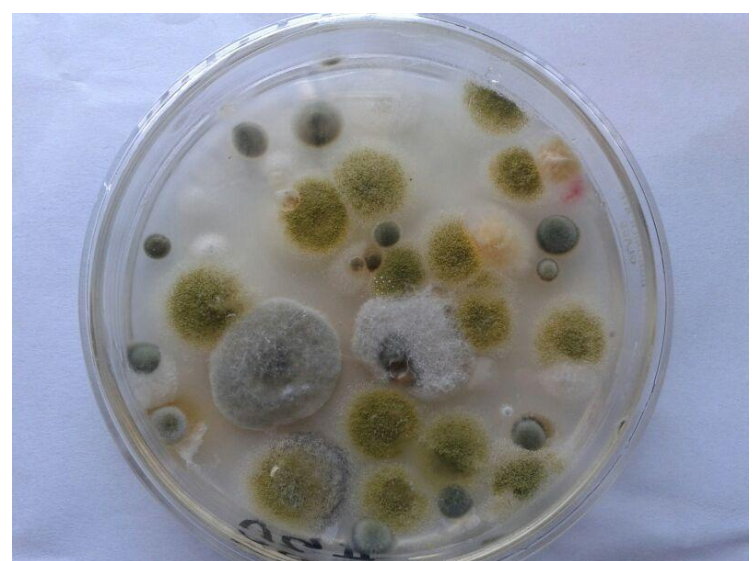

Photo plate 4

Showing later study of Fungal colonies at site II.

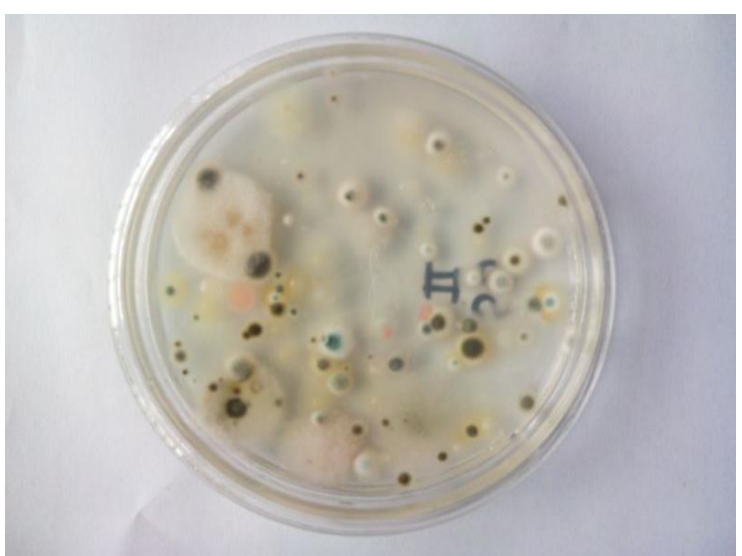

Photo plate 6

Showing later study of Fungal colonies at site III.

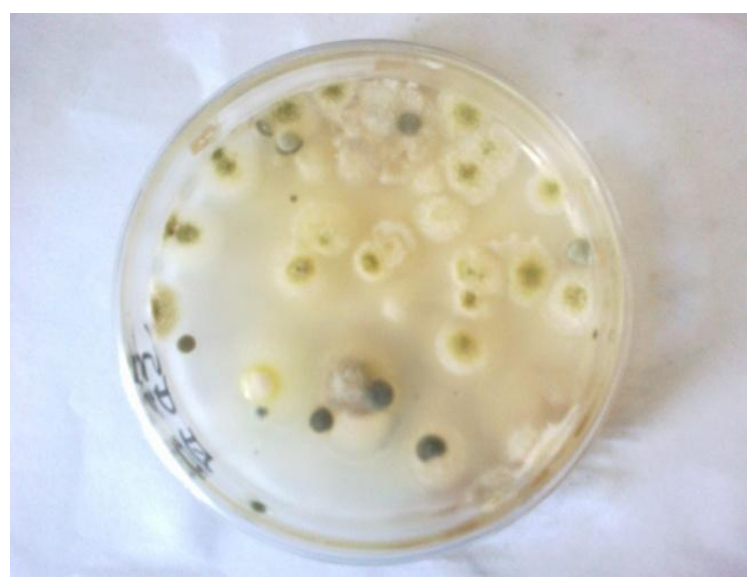

Photo plate 8 Showing later study of Fungal colonies at site IV. 
Some species which were recorded through microscopic examination at $45 x$

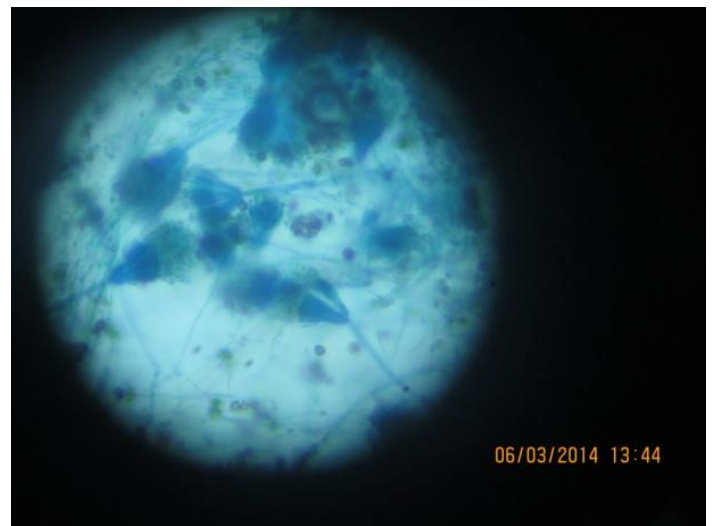

Penicillium

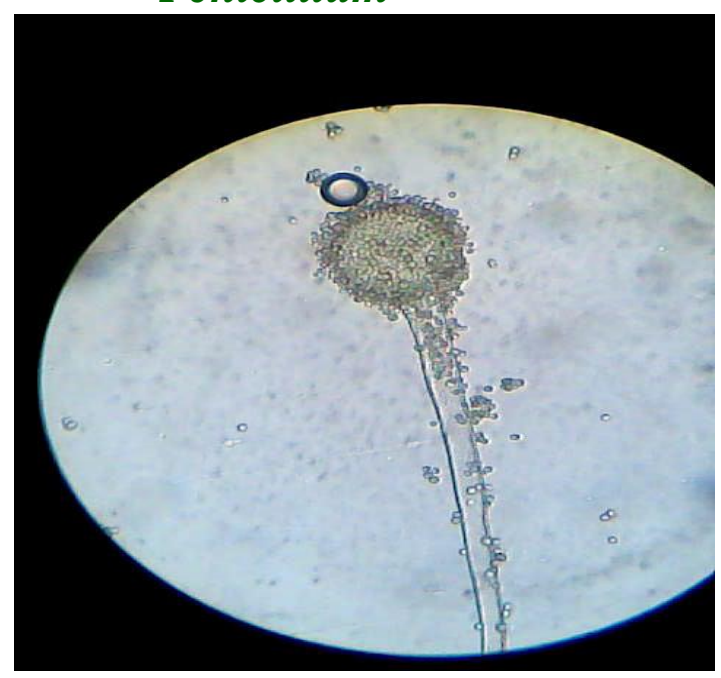

Mucor

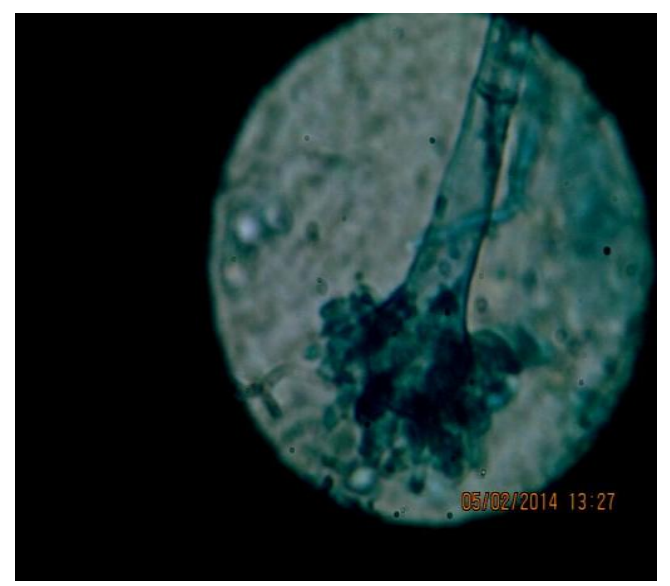

Aspergillus fumigatus

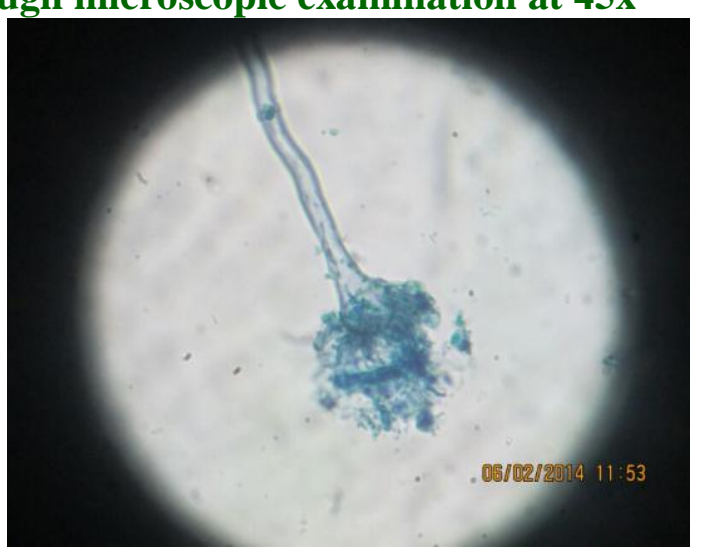

Aspergillus

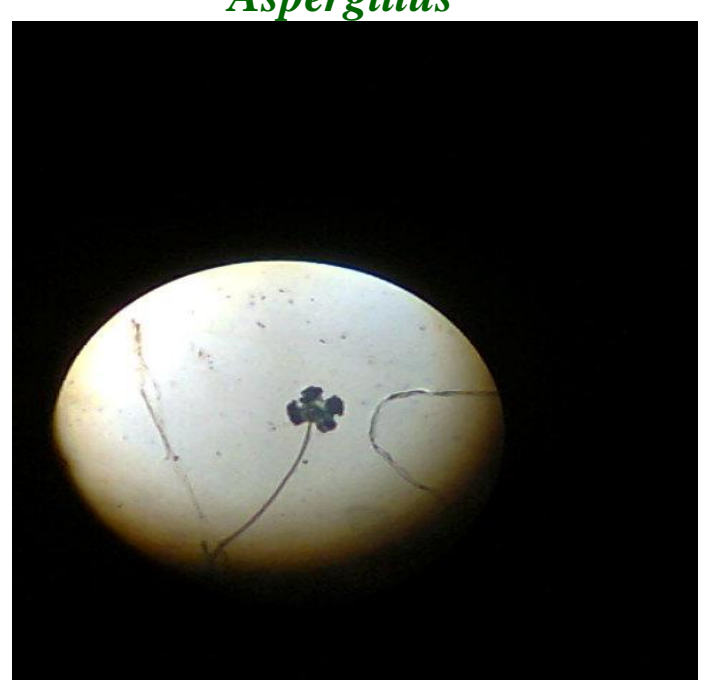

Aspergillus niger

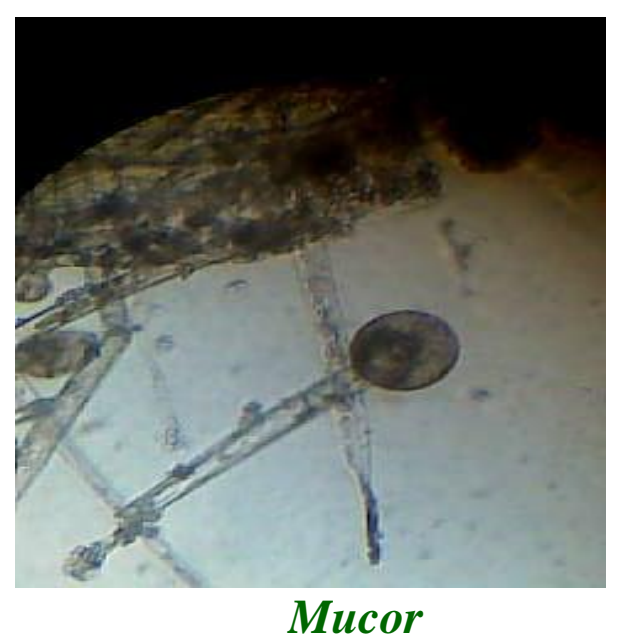




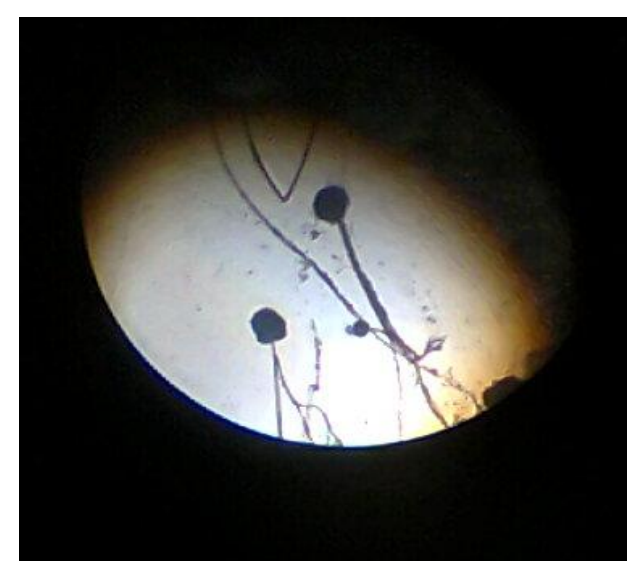

Mortierella

In conclusion, the study revealed that the fungal spores were the major components of the air micro flora of both the outdoor and indoor environment of Haridwar city. The present study showed the variation related with the atmospheric temperature and relative humidity. The maximum number of colonies were recorded from both the outdoor and indoor environment in the month of March due to increase in temperature which showed that an increase in temperature and relative humidity of the atmosphere resulted in increased number of mycoflora qualitatively and quantitatively. (Afzal et al., 2004). Site II has more number of colonies as compared to Site I, Site III, and Site IV due to the heavy vehicular pollution through buses, auto, etc. throughout the day and night and the presence of edibles and other discarded materials at site II.. Among the fungal spores caught from the air, Aspergillus, Cladosporium, Mucor, and Rhizopus were the dominant species at both the circles, traffic circles as well as residential circles. However, Aspergillus was reported as the most dominant species of the outdoor environment and Cladosporium and Rhizopus were reported as the dominant fungi at residential surfaces. Despite limitations of the technique employed and short duration of survey occurred in the area

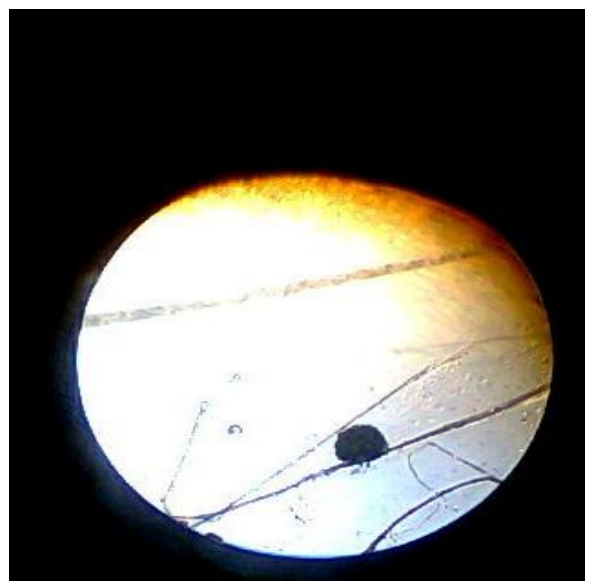

Mucor microsporus

and has revealed the extent and nature of bio pollution of air due to fungal origin at public places. In the future, studies on the dependence of indoor fungal and microbial flora on socioeconomic and hygienic factors will be of interest. Such studies should clarify the relationship between indoor and outdoor fungal microbial flora.

\section{Acknowledgement}

I greatly express my profund gratitude to my guide, Prof. Namita Joshi, Department of Environmental Sciences, Kanya Gurukul Campus, Haridwar for constant support and advice and Dr. Sangeeta Vidyalankar, Coordinator, KGC, Haridwar for providing all necessary facilities to carry out the study.

\section{References}

Adhikari, A., Sen, M.M., Bhattacharya, G.S. 2004. Volumetric assessment of airborne fungi in two sections of a rural indoor daily cattle shed. Environ. Int., 29: 1071-1078.

Adhikari, A., Reponen, T., Lee, S.A., Grinshpun, A. 2004. Assessment of human exposure to airborne fungi in Agricultural confinements: Personal Inhalable sampling Versus Stationary Sampling. Ann. Agric. Environ. Med., 
11: 269-277.

Afzal, M., Mehdi, F.S., Siddqui, Z.S. 2004. Effect of relative humidity and temperature on airborne fungal allergens of Karanchi city, Pakistan J. Biol. Sci., 7(2): 159-162.

Aneja, K.R. 2003. In: Experiments in Microbiology, Plant pathology and Biotechnology (4 ${ }^{\text {th }}$ Ed.) New Edge International Pvt. Ltd., New Delhi.

Awasthi, J.K. 2008. In: Unified Zoology, Shiva Lal Agrawala and Company, Educational Publishers, Indore: 159166.

Chandel, D.S. 2002. Surveillance of Fungal Aeroallergens in two different vegetable market Environments, Indian Allergy Asthma Immunol., 16(1): 55-71.

Das, S., Bhattacharya, G.S. 2008. Enumerating Outdoor aeromycota in sub urban areas of West Bengal, India with reference to respirratoy allergy and Meterologival factors. Annals of Agricultural and Environ. Med., 15(1): 105-112.

Joshi, B.D. 1995. In: Glimpses of
Environmental percepts in Vedic Literature, M/S Ajay M/S Ajay Printers and Publication, Roorkie, India.

Levetin, E. 1995. In: Airborne Fungi in Indoor Environments, Ed. H. Burge, Lewis Publishers, Tulsa.

Levetin, E., Shaughnessy, R., Fisher, E., Bryan, L., Harrison, J., Brennan, T. 2004. Indoor air quality in schools: exposure to fungal allergens. Aerobiologia, (11): 27-34.

Sabariego, S., Diez, A., Gutierrez, M. 2007. Monitoring of airborne Fungi In Madrid (Spain); Acta Bot. Croat, 66(2): 117-126.

Tan, T.K., Teo, T.S., Tan, H., Lee, B.W., Chony, A. 1992. Variation in tropical air spora in Singapore. Mycol. Res., 96: 221-224.

Waggoner, P.E. 1960. In: Plant Pathology: An advanced Treatise (Ed. Horsfall and Dimmod), Academic Press, NewYork.

Watanbe, T. 2002. In: Pictorial Atlas of soil and seed fungi: morphologies of cultured fungi and key to species, Second Edition, CRC Press, Newyork.

\section{How to cite this article:}

Raushani Raj and Namita Joshi. 2016. A Comparative Study of Aeromycoflora in Traffic and Residential Areas of Haridwar City, India. Int.J.Curr.Microbiol.App.Sci. 5(6): 161-170. doi: http://dx.doi.org/10.20546/ijcmas.2016.506.020 